\title{
O Que dizem/SEnTEM alunos PARTICIPANTES De UMA EXPERIÊnCIA De INCLUSÃO ESCOLAR COM ALUNO SURDO ${ }^{1}$ \\ WhAT STUDENTS SAY/FEEL ABOUT THEIR EXPERIENCE OF INCLUSION IN SCHOOL WITH A DEAF STUDENT
}

Cristina Broglia Feitosa de LACERDA²

\begin{abstract}
RESU M O : a educação desurdos tem sido historicamentemarcada por fracassose, mais recentemente, a educação inclusiva tem se apresentado como ad equada para a inserção de al unos surdos na escola. Para atender suas necessidades se criam alternativas como a presença da língua de sinais e de intérpretes. Foram real izadas entrevistas com dois al unos ouvintes e um al uno surdo integrantes de uma $5^{a}$ série do ensino fundamental, na qual foram inseridos um aluno surdo esua intérprete. Os alunos referem à experiência vivenciada como positiva, prazer em terem um colega diferente e conhecer a língua de sinais. Porém, os ouvintes relatam dominar precariamente esta língua, gostariam que el a fossemais fácil e referem saber pouco sobrea surdez. Tais fatos não são percebidos pelo aluno surdo, que vê como adequada sua relação com ouvintes. Há respeito pelas diferenças, mas as relações são superficiais, diversas das vivenciadas por alunos em geral. Conhecer o modo como os alunos significam esta experiência éfundamental para avaliar os efeitos dessa prática.
\end{abstract}

PA LA V RA S-CH A VE: surdez; inclusão educacional; língua brasileira desinais; educação especial.

ABSTRACT: historically, the education of deaf people has been marked by failures and, recently, inclusive education has been defended as adequate for the insertion of deaf pupils in school. In order to attend to their specific needs, alternatives have been created, such as the presence of sign language and interpreters. This study aims to investigate this context by interviewing two hearing and one deaf student from a fifth grade elementary d ass in which there was a deaf student and a sign language interpreter. Thestudents reported that the experience was positive; they enjoyed having a different colleague and coming to know sign language. However, the hearing students said that they had introductory levels of understanding of this language, they wished it was easier to learn, and they understood little about deafness. Such facts were not perceived by the deaf student, who felt his relation to his hearing peers to be adequate. There is respect for differences, but the relations are superficial, different from the general experiences of the other students. Understanding how students give meaning to this experience is essential in evaluating the effectiveness of this practice.

KEYWO RD S: deafness; inclusiveeducation; Brazilian sign language; special education.

\footnotetext{
${ }^{1}$ Esteestudo faz parte da pesquisa realizada como Pós- Doutorado financiada pela FA PESP (01/ 10256-5)

${ }^{2}$ Fonoaudióloga pela UniversidadedeSão Paulo. Mestree Doutora em Educação pela Universi dade Estadual deCampinas, Docente do Curso deFonoaudiologia e do Programa de Pós-Graduação em Educação da Universidade M etodista de Piracicaba. - cristinalacerda@uol.com.br
} 


\section{InTROdUÇão}

A questão da educação das pessoas surdas é um tema polêmico, atual epreocupante. Pesquisas queacompanham os sujeitos surdos em seu desempenho escolar, no Brasil e em outras partes do mundo, mostram que após anos de escolarização estes apresentam uma competência para aspectos acadêmicos muito aquém do desempenho dealunos ouvintes, apesar de suas capacidades cognitivas iniciais serem semel hantes. Tais dados apontam para uma inadequação do sistema de ensino e a urgência de estudos e medidas que favoreçam o desenvolvimento pleno destas pessoas.

Na década de 1990, difundiu-se com força em todo o mundo a política educacional de inclusão dos sujeitos com necessidades educativas especiais, buscando maior respeito esocial ização efetiva destes grupos ea comunidade surda foi atingida por esse movimento. Houve um incentivo maciço para práticas de inclusão de pessoas surdas em escolas regulares (de ouvintes) e desprestigio considerável dos programas deeducação especial. N esse cenário, muitas têm sido as formas dese realizar tal inclusão, todavia, parte significativa dos alunos surdos tem sido submetida a uma escolarização pouco responsável sem que os pressupostos desse projeto educacional sejam respeitados.

Esteartigo pretendefocalizar uma experiência deindusão deum aluno surdo em escola regular, com a presença deintérprete delíngua de sinais eavaliar aspectos dessa experiência do ponto devista dos al unos implicados nesta atividade. Para tal, foram real izadas entrevistas com al unos ouvintes e al uno surdo e serão analisados seus depoimentos procurando refletir sobre esta vivência e suas implicações.

\subsection{Surdez e Linguagem}

A aquisição eo desenvol vimento da linguagem são fundamentais para a construção de processos cognitivos e para que sejam estabelecidas as relações sociais. A linguagem é responsável pela regulação da atividade psíquica humana, pois éela que permeia a estruturação dos processos cognitivos eéassumida como constitutiva do sujeito, pois, possi bilita interações fundamentais para a construção do conhecimento (VYGOTSKY, 2001). Os sujeitos surdos, devido à defasagem auditiva que possuem, encontram dificuldades para entrar em contato com a linguagem do grupo social no qual estão inseridos (GÓES, 1996). A linguagem, além desua função comuni cativa, interferesignificativamente na organização do pensamento, sendo essencial para o desenvolvimento cognitivo. Assim, no caso de crianças surdas, o atraso de linguagem pode trazer como conseqüências problemas emocionais, sociais e cognitivos, mesmo que haja o aprendizado de uma língua tardiamente.

A linguagem, entendida como adquirida nas interações e relações sociais, em sua modalidade oral, faz parte da vida do sujeito ouvinte desde muito 
cedo. É no contato com ela, fazendo parte de uma sociedade que faz uso dela que o sujeito adquire linguagem. No caso de pessoas surdas, esse contato não se dá de modo natural, pois a língua oral é percebida por meio do canal auditivo sendo, portanto, inacessível à criança surda.

A idéia dequea linguagem éadquirida na vida social remete, também, ao conceito dequeéna/ pela/ com alinguagem queo sujeito se constitui, com suas características tipicamente humanas, diferenciando-se dos demais animais, caracterizando assim a relevância da linguagem para o desenvolvimento (VYGOTSKY, 2001).

Nestesentido, observa-sequeas crianças surdas, devido às dificuldades acarretadas pelas questões de linguagem, encontram-se defasadas no que diz respeito à escolarização, sem o ad equado desenvolvimento ecom um conhecimento aquém do esperado/ desejado para a idade. Vem daí a necessidade de criação de propostas educacionais que atendam às necessidades dos sujeitos surdos, a fim de favorecerem o desenvolvimento efetivo de suas capacidades. N a busca pela mel hor saída para tais problemas várias abordagens e práticas pedagógicas são utilizadas (MOURA, 1999, LACERDA; MANTELATO, 2000). N a década de 1960, surgem os primeiros estudos sistematizados acerca da língua de sinais. Partindo do conhecimento sobre as línguas de sinais emerge a proposta de educação bilíngüe que assume como língua dos surdos a língua desinais, sendo esta, portanto, a que deveser adquirida primeiramente. É a partir desta língua queo sujeito surdo entrará em contato com a língua majoritária, que será sua segunda língua. Entende-se que adquirindo a língua de sinais a criança surda poderá desenvolver-se, no que diz respeito aos aspectos cognitivos elingüísticos, de acordo com sua real capacidade, do mesmo modo que ocorre quando as crianças ouvintes aprendem a falar. Sobre estas questões Tartuci (2001) afirma que:

\begin{abstract}
O bilingüismo tem como meta educacional viabilizar a presença de duas línguas no contexto escolar do aluno surdo. Entende-se que, ao valorizar e tornar acessível o uso da língua natural dos surdos, essa vivência oportunizará que ele construa uma auto-imagem positiva e, ao mesmo tempo, se desenvolva cognitiva e lingüisticamente, o que trará repercussões importantes na sua formação enquanto pessoa. Também, o domínio da língua de sinais facilitará o aprendizado da língua dos ouvintes, como segunda língua (TARTUCI, 2001, p. 34).
\end{abstract}

\title{
1.2 A inclusão escolar
}

O tema inclusão escolar tem sido debatido em âmbito mundial. Muitos países assumiram a inclusão como tarefa fundamental da educação pública ea partir de diversas tentativas de viabilizá-la surgiram inúmeros debates e controvérsias na área.

Os defensores da inclusão, como Bunch (1994), Cohen (1994), Kirchner (1994), Silveira Bueno (1994) eSassaki (1997) argumentam quetodos os estudantes 
devem ter as mesmas oportunidades de freqüentar classes regulares próximas ao local desua residência, com crianças demesma faixa etária, ou freqüentar a mesma escola que seus irmãos. Reconhecem que para isso se faz necessário um programa educacional adequado às capacidades dos diferentes alunos, e indicam ainda a importância deoferecer suportee assistência às crianças com necessidades especiais e aos professores para que esta integração seja a melhor possível e defendem também queas escolas especiais ea formação de pessoal qual ificado para essetipo de trabal ho devam ser manti das, já que certas crianças demandam uma atenção realmente diferenciada, ea escola especial pode ser o recurso mais indicado.

A defesa destemodelo educacional ésustentada por uma filosofia que advoga a solidariedadee respeito mútuo às diferenças individuais, argumentando que a educação especial, como desenvolvida anteriormente, favorecia a estigmatização e a discriminação. Todavia, vários problemas são percebidos na implementação desta proposta. A criança com necessidades especiais édiferente, eo atendimento às suas características particulares implica em formação, cuidados individualizados, revisões curriculares que não ocorrem apenas pela vontade do professor, mas que dependem de um trabal ho de discussão eformação que envolve recursos eque efetivamentenão tem sido realizado.

A inclusão seconstitui mais como umaboa proposta para a comunidade em geral, que se mostra aberta ao contato com as diferenças, do que realmente adequada para aqueles que, tendo necessidades especiais frente ao seu desenvolvimento escolar, necessitam de uma série de condições que, na maioria dos casos, não têm sido propiciadas.

No final da década de 1970 e início da década de 1980, a educação brasileira buscou novas diretrizes, com fortalecimento da mobilização pela Integração Escolar, que já vinha sendo discutida na década de 1960, e que tinha por finalidade ultrapassar a segregação, construindo espaços comuns na sociedade, visando "tornar a pessoa com deficiência ou distúrbio parte integrante da sociedade" (TARTUCCI, 2001, p. 64). É a partir da década de 1990, quea corrente em defesa da Integração Total ganha força, sofre influência da Declaração de Sal amanca (1994) eé renomeada inclusão.

Deacordo com Sassaki (1997), a principal mudançaéqueno movimento del ntegração Escolar o aluno deveria seadaptar à escola, ao contrário do que prevê a política del nclusão, em quea escola équedevese adaptar para atender a todos os alunos. Assim, a opção pela política deinclusão acompanha um movimento mundial e define-se como meta a garantia de que todos os alunos tenham acesso ao ensino regular, confrontando assim as discussões sobreinclusão e educação especial .

Inclusão, nesse contexto, implica o compromisso que a escola deve assumir de educar cada criança, contemplando a pedagogia da diversidade, pois todos os alunos deverão estar dentro da escola regular, independente desua origem social, étnica ou lingüística. Deste modo, a implementação da inclusão pressupõe um model o no qual cada criança éimportante para garantir a riqueza do todo, ou 
seja, é desejável que na classe regular haja todo tipo de al uno. Para tal, a escola deveser criativa no sentido de buscar soluções visando à manutenção desse aluno no espaço da sala de aula regular, levando-o a obter resultados satisfatórios em seu desempenho acadêmico esocial (MAZZOTA, 1996). Todavia, tais resultados satisfatórios só podem ser al cançados pela criança com necessi dades especiais se no espaço escolar for contemplada sua condição lingüística, cultural ecurricular especiais.

A Inclusão Escolar éum processo gradual edinâmico que podetomar formas distintas de acordo com as necessidades dos alunos. A credita-se que essa integração possibilite a construção de processos lingüísticos adequados, de aprendizado dos conteúdos acadêmi cos e uso social da leitura e da escrita. Nessa proposta o professor media e incentiva a construção do conhecimento através da interação com elee com os col egas.

Quando se opta pela inserção do aluno surdo na escola regular, esta precisa ser feita com muitos cuidados que visem garantir sua possibilidade de acesso aos conhecimentos que estão sendo trabal hados, além do respeito por sua condição lingüística e por seu modo peculiar de funcionamento. Isso não parece fácil de ser alcançado e, em geral, vários desses aspectos não são contemplados, como o fato do surdo, em geral, não ter uma língua compartilhada com seus colegas e professores, e de estar em desigual dade lingüística em sala de aula (BOTELHO, 1998; LACERDA , 2000).

Assim, acreditar que valores e princípios da educação inclusiva são capazes de promover instituições mais justas do queàquel as que fundamentaram a segregação; compreender que o discurso em defesa da inclusão se constituiu historicamente como oposto ao da segregação e, nesse contexto, reconhecer a importância de destacar as vantagens da educação inclusiva, não podeocultar os problemas todos que esta mesma E du cação I nclusiva impõe.

[...] a questão nuclear em relação à real ização dos ideais da educação inclusiva remete, no nosso país eem outros países em desenvolvimento, à desi gual dade social típica dessas sociedades. A análise dastendências quemarcam o processo de globalização não deixa dúvidas quanto aos valores que privilegia e aos modos como se organiza. No contexto do acirramento das diferenças sociais provocado pelas tendências gl obalizantes, pela concentração deriqueza e pelos processos quea acompanham (redu ção do emprego, encol himento do Estado, etc.) a implementação de políticas real menteinclusivas deveenfrentar grandes problemas.

O elogio da inclusão apresenta a vantagem dearrolar argumentos para a defesa das políticas inclusivas. Mas para que seja realmente eficaz é preciso que o discurso se feche sobre si próprio, aparecendo como uma total idade que não admitequestionamentos (LAPLANE, 2004, p. 17-18).

A fraqueza da inclusão, porém, esta no fato de que em certo momento, o discurso contradiz a realidade educacional brasileira, caracterizada por classes superlotadas, instalações físicasinsuficientes, quadros docentes cuja formação deixa a desejar. Essas condições de existência do sistema educacional levam a questionar 
a própria idéia de inclusão como política que, simplesmente, insira alunos nos contextos escolares existentes. A lém disso, ao circunscrever a inclusão ao âmbito da educação formal eignorar as rel ações desta com as outras instituições sociais, esse discurso apaga o quadro detensões e contradições no qual a política inclusiva seinsere (LAPLANE, 2004).

Em função do contexto apresentado acima, pretende-se focalizar uma experiência de inclusão em escola regular, com a presença de intérprete de língua desinais avaliando aspectos dessa vivência do ponto de vista dos alunos ouvintes esurdo buscando conhecer melhor aspectos desta prática.

\section{Desenvolvimento - contexto da Pesquisa}

A sal a de aula focalizada é uma quinta série do ensino fundamental, de uma escola da rede privada, que conta com 29 alunos ouvintes, uma criança surda eduas intérpretes de língua desinais que se revezam nestetrabal ho. A faixa etária dos al unos varia de 10 a 12 anos, sendo 17 meninas e 12 meninos. A criança surda, queserá chamada de Gustavo, ${ }^{3}$ éacompanhada de intérpreteeducacional , desde a pré-escola. Ele freqüenta a escola focalizada neste estudo há um ano e meio. Para essa escola é a primeira experiência com aluno surdo e intérprete em sala de aula. A criança, com 12 anos deidade, apresenta surdez profunda bilateral, adquirida por meningite aos 3 anos de idade, ${ }^{4}$ filha de pais ouvintes, não tem domínio do português fal ado eé usuária da Língua Brasileira deSinais (Libras).

Quando da entrada de Gustavo nesta escola a direção se mostrou interessada pelo processo de inclusão com a presença de intérprete de Libras e afirmou queseria feito um trabal ho conjunto: coordenação, professores, intérprete, família, fonoaudióloga e al unos para o sucesso da inclusão. Todavia, apesar das solicitações feitas pelas intérpretes e pela fonoaudióloga não foram realizadas reuniões de planejamento para oferecer maiores informações sobrea surdez, sobre o aluno surdo, sobre a adequação das estratégias em sal a de aula, esobre o papel do intérpreteaos novos professores da $5^{a}$ série. A direção da escola prometeu tais reuniões, mas não as realizou al egando falta de horário disponível nos encontros para o planejamento mais geral da escola. A escola julgava a inclusão bastante satisfatória e não via necessidade de discussões ou trocas mais freqüentes.

Na dassefocalizada, são oito os professores responsáveis pelas diversas disciplinas ministradas: Português, Matemática, Inglês, Ciências, Geografia, História, Educação Física e A rtes. As aulas são de 50 minutos e os professores se alternam ministrando suas aulas. As dinâmicas de aula variam de acordo com cada professor e com os conteúdos a serem apresentados, mas há um predomínio de aulas expositivas com uso preferencial do quadro negro como apoio para as

\footnotetext{
${ }^{3}$ Todos os nomes atribuídos a sujeitos nesta pesquisa são fictícios, resguardando sua identidade.

${ }^{4}$ Sua meningite foi muito agressiva, deixando lesões difusas no hemisfério esquerdo e tálamo (visíveis ao exame deneuro-imagem) e, como conseqüência, a linguagem oral que ele apresentava anteriormente ao quadro infeccioso desapareceu após uma semana de permanência na unidade de terapia intensiva.
} 
explicações e uso delivro didático. Eventualmente, são usados vídeos, mapas ou transparências. Em geral, os alunos assistem e participam respondendo a perguntas em aulas expositivas, ecom al guma freqüência são real izadas atividades em grupo na classe, com grupos que se al ternam não tendo uma configuração estável.

O aluno surdo estava sempre acompanhado de uma das intérpretes (eram duas que se revezavam em dias alternados da semana) e estas se sentavam ao seu lado, ou na frente da classe, dependendo do tipo de atividade proposta pelos professores.

\subsection{Entrevistas e sujeitos entrevistados}

Para esta pesquisa foi realizado esclarecimento sobre os objetivos e procedimentos para: direção e coordenação da escola, professores, al unos ouvintes, aluno surdo, famílias dos alunos ouvintes, família do aluno surdo e intérpretes. A pós, os participantes assinaram o termo de consentimento livre e esclarecido (conforme processo CEP-Unimep 84/ 03).

Para as entrevistas ${ }^{5}$ com os alunos ouvintes, buscou-se sondar quais alunos estariam mais disponíveis para participar a partir de sugestões do aluno surdo, intérpretes e família do aluno surdo. Tais alunos foram contatados, bem como suas famílias, edepois devárias tentativas, uma das alunas (Silvia) interessada em participar sugeriu que o pesquisador fosse até sua casa, que ela convidaria uma outra colega de classe (Débora) para que então fosse realizada a entrevista. Deste modo, a entrevista foi realizada com duas alunas ouvintes da classe de Gustavo. Elas solicitaram quea entrevista fosse feita com a dupla, porque disseram que se sentiam envergonhadas de serem entrevistadas sozinhas. A entrevista com as duas crianças foi registrada em áudio.

Silvia, de 11 anos, estava na classe de Gustavo desde a quarta série e, portanto, o conhecia bem eestava experimentando pelo segundo ano a experiência deter em classe um companheiro surdo esua intérprete delíngua desinais. Débora, também com 11 anos, apenas nesteano conheceu Gustavo eparticipava desua classe. A entrevista foi realizada no segundo semestre letivo, no final do mês de agosto.

Entrevistar alunos ouvintes que participam dos processos de inclusão é uma prática pouco freqüente. Poucas são as pesquisas que trazem dados sobre como se sentem estes alunos, que dificuldades encontram eque comentários têm a fazer sobre esta realidade(STINSON ; LIU, 1999). É muito comum em pesquisas na área de educação não selevar em conta, ou não buscar saber a opinião dos al unos, princi pais protagonistas da cena focalizada. Assim também, pouco édiscutido na literatura sobre estratégias metodológicas deacesso a dados a partir dos alunos, e isso émenos freqüente ainda com alunos mais novos (menores de 14 anos). Desta forma, para ouvir as crianças envolvidas a entrevista teve queter uma participação

\footnotetext{
${ }^{5} \mathrm{O}$ rotei ro das entrevistas encontra-se como A pêndice no final do artigo.
} 
mais intensa do pesquisador, configurando-se como um instrumento útil deacesso às informações.

O aluno surdo foi entrevistado pela pesquisadora e uma intérprete (diferente daquelas que o seguem em sala de aula, porém sua conhecida) para garantir quea comunicação em Libras fosse plenamente satisfatória. A entrevista foi filmada para possibilitar a transcrição adequada da Libras. Os padrões de transcrição foram apoiados nos critérios de Lacerda (1996) e serão detal hados quando da análise do material.

Gustavo conhecia a pesquisadora há bastante tempo, e nesse sentido não houve qualquer constrangimento entre os presentes. A intérprete foi responsável pela mediação da entrevista e também pela transcrição da mesma, pelo seu conhecimento maior em língua de sinais. A entrevista foi realizada em um local previamenteacordado fora do espaço escolar, no segundo semestreletivo, no início do mês de agosto.

A entrevista transcorreu demodo um pouco diverso daquela realizada com as crianças ouvintes, já que Gustavo apresentava respostas curtas e pontuais, sendo necessária uma intervenção mai or da pesquisadora. Muitas vezes, foram introduzidas questões que simulavam uma certa situação procurando conhecer suas reações diante delas, ou exemplos para que ele expressasse suas opiniões. Alguns conceitos também foram pesquisados para ter maior clareza de como ele via sua situação escolar com a presença deintérprete.

A s entrevistas duraram em média uma hora emeia cada uma eforam transcritas integralmente para posterior análise.

\section{Resultados}

\subsection{Análise das entrevistas com alunos ouvintes}

Para melhor compreensão o material das entrevistas foi organizado a partir de núcleos temáticos, procurando identificar os principais temas tratados nos diferentes momentos da entrevista. Assim, trechos das entrevistas foram recortados e trazidos para análise, a partir dos seguintes núcleos temáticos: Conhecimento sobre Língua deSinais, Relação entre alunos ouvintes eintérprete, Relação entrealunos ouvintes ealuno surdo, Representação que os alunos ouvintes têm do aluno surdo, Informações sobre a surdez e Dificul dades de comunicação entrealunos ouvintes ealuno surdo.

\section{Conhecimento sobre Língua de Sinais}

Débora: como el e senta quase do meu lado, daí eu tento fazer (sinais). Silvia: a intérprete do outro ano, ela ensinou bastante coisa pra gente, para saber, principalmente para os professores, né, para ir no banheiro, sair da sala de aula, essas coisas. 
Débora: A h, éque um dia, na $6^{a}$ feira, né, um dia a intérprete, ela, ela falou, ele assim, ela falou assim, que ele ia dar nomes, só que não deu tempo, então ele deu só para alguns.

Silvia: para mim eu acho que é divertido né, parece até que a gente está brincando né...,

Pelos depoimentos das alunas pode-senotar quedemonstram interesse pela língua de sinais ${ }^{6}$. Dizem procurar se comunicar diretamente com o aluno surdo efazem isso apoiadas em sinais que conhecem equeaprendem nas interações com o aluno ecom sua intérprete. Silvia e outros al unos aprenderam al guns sinais apresentados pela intérprete no ano anterior e ela relata fazer uso deste conhecimento, demonstrando em seu depoimento se sentir segura em conversar com Gustavo em al guns contextos de interlocuções bastante simples. Todavia, é importante salientar que se trata de um léxico muito restrito que só possibilita trocas num contexto fechado, não configurando um conhecimento da língua de sinais propriamente.

Débora também procura conversar com ele, ejustifica que por sentarse perto dele na sala de aula isso fica mais fácil. A mbas atribuem à intérprete o papel de ensinar sinais quesão úteis para as conversações.

Na escola, foi incentivada a prática, desdeo ano anterior, de Gustavo atribuir sinais aos seus colegas ouvintes ${ }^{7}$, criando a possibilidade deles se apresentarem e Gustavo (re)conhece-los pel os sinais já quenão ouve seus nomes. Silvia recebeu seu sinal no ano anterior, Débora, porém, relata que não recebeu seu sinal neste ano porque 'não deu tempo' deixando ver que estas atividades ocorrem, mas que não são uma prioridade no espaço escolar. A entrevista foi realizada em agosto eatéentão a al una não tinha um sinal, apesar de sentar-seao lado do aluno surdo ese considerar próxima a ele.

De modo geral, as alunas referem queaprender sinais com Gustavo e com a intérpreteé divertido e parece sentirem-se bastante a vontade diante desta tarefa. A experiência com aprendizagem delíngua de sinais por al unos ouvintes tem sido discutida por al guns autores (CAPIRCI et al, 1997; ROSSELA, 2000/ 2001) que indicam que as crianças não têm muitas dificuldades para aprender alguns aspectos da língua de sinais e que se beneficiam desta aprendizagem uma vez que são estimuladas a uma série de reflexões sobre a linguagem ea uma atenção visoespacial concentrada que as auxilia de maneira geral em outras áreas de aprendizagem.

Entretanto, uma experiência deinclusão dealunos surdos, relatada em Teruggi (2003), aponta para limites importantes. A autora descreve quea inclusão dealunos surdos foi bastante planejada e todos os al unos ouvintes contavam com

\footnotetext{
${ }^{6}$ Língua de sinais é entendida aqui como a língua completa com todos os seus elementos queé usada apenas pelo al uno surdo e pela intérprete. A s al unas aprenderam a usar al guns sinais, mas não a língua propriamente e por isso será feita uma diferenciação entre uso de língua desinais euso desinais.

${ }^{7} \mathrm{~A}$ comunidade surda atribui sinais às pessoas quesão usados como ‘nomes'. U m surdo se refere às pessoas pelo seu sinal, nomeando-a.
} 
pelo menos duas horas semanais de aulas delíngua de sinais, ministradas por um professor surdo fluente. Ainda com ensino dirigido, em relação ao uso e conhecimento da língua de sinais, observou-se que há uma forte influência da língua oral tanto nas produções de alunos surdos como nas produções de al unos ouvintes, equeestes últimos, em particular, constroem a língua desinais apoiada nos esquemas da língua oral, e usam freqüentementea datilologia para expressar significados para os quais não conhecem os sinais. Os al unos ouvintes são capazes, após al guns anos de trabalho de usar um tipo de língua sinalizada, mas não se apropriam da língua desinais real mente. Os dados coletadosenfatizam quealíngua de sinais presente no contexto escolar é uma língua principal mente de tradução, usada pel os intérpretes (nem sempre corretamente) para possi bilitar o acesso aos conhecimentos, equeseria desejável para um conhecimento adequado da língua o contato coma comunidadesurda fazendo uso da língua desinais deformafluente.

\title{
Relação entre alunos ouvintes e intérprete
}

\begin{abstract}
Silvia: Quando a gente quer perguntar al guma coisa assim para ele, é a gente mesmo, não pedir para a intérprete, é perguntar, então a gente fal a como éque é assim, como é que é aquilo! Aí ela vai mostrando o sinal, aí a gente vai perguntando, né, porqueé assim, como é mais difícil com ele porque ele não sabe fazer assim só com a língua, só letras, é, tem que ser gestos mesmos, né. Débora: A h, depende, porque assim, équando eu sei os gestos, daí eu mesmo pergunto para ele, mas quando eu não sei, peço ajuda para a intérprete.

Silvia: Não, só atrapalha um pouquinho, né, porque quando ele quer ler a tarefa que el efez, né, porque aí el e também tem uns gestos que ele não sabe, né; então ele vai, ela vai falando para ele, ele vai fazendo, então é um pouco demorado.

Silvia: quando a intérprete do ano passado não podia ir no ensaio, aí era a Laura, eu ea Marcia que ficava na frentelá para ele. Só que eu achava, eu não era assim tão boa né, então deixei quea Laura ea Marcia ficasse, então eu não fal ei para ele. Mas a maioria das coisas assim, mais importante, a gente sabe falar com ele, né.
\end{abstract}

As alunas falam sobre as intérpretes demodo afetuoso, não parecendo ter problemas na relação com elas. Buscam contato direto com o aluno surdo e recebem delas informações de sinais que não conhecem e que precisam para conversar com ele. Outras vezes, percebem que querem conversar sobreargumentos mais complexos e pedem que a intérprete medeie às relações, se mostrando satisfeitas com estetrabal ho. Todavia, Silvia faz um comentário interessantesobre o fato de Gustavo não compreender tudo apenas com o uso da datilologia, e que eleprecisa dos 'gestos mesmo' (!!!). Isso indica quee la buscou secomunicar sol etrando palavras, e que a intérprete interferiu apontando a inadequação deste modo de comunicação. Assim, os conhecimentos que ela tem sobre língua de sinais se mostram parciais einsuficientes muitas vezes.

As alunas parecem satisfeitas com o trabalho das intérpretes que mediam as relações eque não intervêm senão são solicitadas abrindo espaço para que ocorra a comunicação entre os alunos. A utores como Yarger (2001), referem 
queo intérprete tem papel central na relação entreal unos surdos e ouvintes, eas próprias alunas confirmam isto com seus depoimentos. Entretanto, elas referem que, às vezes, o trabal ho de tradução atrapal ha a aula quando a intérpretetraduz para classeuma leitura deGustavo, por exemplo, ea classe precisa prestar atenção, mas como ele lêcom dificul dade, isso é demorado. Interessante notar que o al uno surdo é submetido a esse trabal ho quase o tempo todo que está em sala ficando atento às traduções que a intérprete faz das produções orais (mais fluentes provavelmentequesua leitura), mas que exigem deleatenção constante, eisso não pareceser notado pel os ouvintes. A atenção mais prolongada ao uso delíngua eas dificuldades de compreensão não são motivadoras para os alunos ouvintes.

Quando a intérprete não está presente por alguma razão procuram assumir seu papel, demonstrando saber que el a cumpre uma função importante para o aluno surdo. Silvia reconhece em outras alunas uma maior fluência em sinais mas, às vezes, procura tomar para si esta tarefa. Todavia, isto indica uma percepção lúdica do papel da intérprete: é como sefosse fácil substituí-la porqueo que ela faz, a língua de sinais, elas podem fazer também. Os alunos ouvintes parecem acreditar quea língua de sinais seja muito simples, e queas necessidades delinguagem do aluno surdo sejam facilmente atendidas.

\section{Relação entre alunos ouvintes e aluno surdo}

Silvia: eu sei fazer só que eu tenho vergonha depedir. É, ... éeu sei o sinal , é, mas éque pra pedir eu acho quenão consigo assim....É, etambém tenho medo que na hora que el e fala não, né, daí eu vou ficar com a cara...

Silvia: Mas a Débora brinca mais com ele do que comigo, né, porquecomo ela está do lado, então el a começa a brincar, aí, tem um meni no chamado Vinícius, né, toda vez queéna hora assim, que dá quea gente pode conversar na classe, el evai direto já com ele, el es começam a brincar, fala também com a intérprete, com a Flávia, né, ele bem.......

Silvia: a gente fica brincando com ele assim, a gente escreve o nome dele e começa a fazer coração, começa a fazer gesto que gosta, eaí el e começa a brincar, elecorreatrás da gente, é divertido.

Nos trechos aqui apresentados se observam relatos quefalam de como as alunas vêem o amigo surdo integrado aos demais. Elebrinca com vários alunos, éprocurado por vários deles ese mostra bastanteinserido nas atividades realizadas pelas crianças.

Todavia, chamam a atenção certos jogos que Silvia relata fazer com ele (corações queindicam quem seria a 'namorada' dele, ou dizer queficou com ciúmes) queparecem ser infantilizados para a idade deles equepodem indicar relações menos elaboradas pelas restrições impostas pel o pouco conhecimento desinais, ou por uma representação dele como 'diferente'. Ela diz ter vergonha de pedir material emprestado para ele (na situação da entrevista foi perguntado sobre pedir um lápis, ou uma borracha) indicando a pouca intimidadee pouca flexibilidadedesta relação, já que pedir um material escolar emprestado éal go muito comum em sala deaula. 
Entretanto, sua surdez e sua língua diferenciada não parecem excluílo das atividades entre os al unos que o convidam e se convidam para um contato mais próximo com ele. A relação entreosalunos éreferida como al go quetranscorre sem dificuldades aparentes, mas pelo domínio precário de língua de sinais dos alunos ouvintes, se pode deduzir queo aluno surdo não mantém um diálogo mais estruturado ou aprofundado com eles. Falar deseus desejos, desuas dúvidas, fazer comentários irônicos ou mal iciosos (comuns nessa faixa de idade) não se mostra possível. Assim, o queévisto como uma boa relação setrata deum contato amistoso, porém, restrito.

\section{Representação que os alunos ouvintes têm do aluno surdo}

Silvia: É, que nem um aluno normal, pra gente, às vezes, a gente até esquece, tem vezes que a gente quer brincar com ele, a gente, aí a gente assim: "Gustavo?", só que sem fazer gestos nem nada, ele ol ha assim para a gente, sabe, nossa, outro dia a genteestava faland o assim: - “Gente, essemenino escuta, elefala, ele está fingindo, não sei o que, el equer confundir nossa cabeça, não sei o quelá!"; sei lá...

Débora: Eu acho el e muito inteligente...Eu acho, apesar do problema dele, ele émuito bom.

Silvia: N ossa, el eémuito, ele, tudo o queel a fala ele entendena hora enossa, todas as provas ele só tira nota boa, ele é muito bom.

Silvia: aí el e começa montar histórias dele mesmo, é bem legal. Quando não tem nada para fazer ele desenha, nossa, eu falo para Débora:-“não sei como ele consegue!", né, ficar cansado, porque toda hora a gente vêele desenhando lá, no maior pique. É bonito.

As alunas mostram reconhecer, no aluno surdo, certas qualidades. Ele é representado como alguém inteligente, que tem um bom desempenho escolar geral, como um ótimo desenhista. Isto o torna al guém respeitável, apesar de sua surdez, como comenta Débora.

O fato deele ter áreas de desempenho acima da média (nos desenhos, ou em matemática) parece lhe conferir uma qualidade especial. Ele é valorizado por aquilo que sabe conhecee as crianças se mostram atentas às suas produções, aos modos com é avaliado e a adequação disso. Nesse sentido, é visto como um aluno que pertence à classe, e como tal é observado eavaliado por seus membros. Já as dificuldades deste aluno, principalmente relacionadas à leitura e escrita parecem ser pouco evidentes para as alunas ouvintes enos depoimentos delas só ganham destaques as suas conquistas.

\section{INFORMAÇõES SOBRE A SURDEZ}

Silvia: ele tenta assim ler os lábios da nossa boca, né, a gente vai fazendo qualquer jeito para dar certo. Eu já sei um pouquinho mesmo.

Débora: (falando de outro aluno surdo da escola) ele é surdo só que ele fala, ele um dia, ...Um dia meu irmão, ele fal ou que el e né, foi chamar a professora, ele deu um grito, por que el e não sabe... É assim al tura, que el efala, então ela 
dá, dá, grita ou se não fala muito baixo, daí não, como elefalar normal assim...

Silvia: eu acho queépor que elenasceu assim, ou senão por que, não por que, eu sei só com três anos mesmo que eu acho que ele teve um problema queele ficou assim, e aí ele lembrou como falava papai, mamãe, aí ele pegou e falou na classe, sabe, nossa, agora eu falei para minha mãe, minha mãe ficou emocionada, por que ele conseguir falar, aí a gente fal ava:- "Fala meu nome, fala meu nome", ele falava, aí ele, parece até que el e esta falando normal, ele fala um pouco de dificuldade, mas fala...

Silvia: e não tem noção se ta muito al to ou baixo, ele dá cada risada alta. Um dia el efoi, a professora fal ou para o Gustavo pegar um trabalho, ele arrastou a cadeira efez aquele barulho, bem alto, el eficou assim .....

A pesar deSilvia conviver com Gustavo há um ano emeio e Débora há mais de um semestre as duas mostram ter poucos conhecimentos sobre a surdez, sobre suas causas, esobre comportamentos típicos das pessoas surdas. Tudo o que ocorrenesteâmbito gera surpresa, curiosidade einteresse que não parece ter sido aproveitado pela escola.

Silvia fala deuma possível leitura labial feita pelo aluno surdo, todavia estealuno praticamentenão faz uso deste recurso. $O$ fato do falante fal ar mais ou menos pausadamente para eleo ajuda pouco, porque eleconcentra toda sua atenção na língua de sinais e é a partir dela que constrói suas referências. Silvia revela manter com eleuma relação de comunicação que, às vezes, se baseia em al go pouco efetivo para Gustavo, levando a problemas bastante importantes, já que ela considera queele esteja compreendendo tudo.

Outras vezes, emissões orais dele são confundidas com fala, e com a idéia dequeelea qual quer momento vai falar, passando afazer parte'magicamente' do grupo dos falantes (e porque não dizer ouvintes). São crenças que não contribuem para uma relação realística entre eles, contando com aquilo que ele efetivamentepode apresentar.

Comportamentos típicos desurdos como rir alto, sem perceber o volume desua voz, ou fazer rumores exagerados com móveis ou ao andar são consideradas esquisitices, coisas que causam estranheza, quando poderiam ser discutidas mostrando porque isso ocorre, eporque são características das pessoas surdas que chamam a atenção dos ouvintes. São pequenos detalhes que podem contribuir para um reconhecimento positivo ou negativo de suas características, equeprecisam ser discutidas num contexto que se pretende inclusivo.

\section{Dificuldades de comunicaÇão entre alunos ouvintes e aluno SURdo}

Silvia: A gentejá em dupla, mas éum pouquinho difícil, porque, sei lá, a gente não tem muito como falar com ele, né, que nem, tem vezes que até fico desesperada, porqueeu quero falar com ele, néeeu não consigo, ea intérprete não está do lado, né, então eu fico: “Aí Débora, onde vocêestá, não sei o que, ...", mas no final eu consigo falar com ele, eu escrevo, aí a gente vai se entendendo aos pouquinhos. 


\begin{abstract}
Silvia: (Sobre as atividades fora da sala de aula - educação física) é normal a gente brinca com ele, tenta falar, o que a gente não consegue, nossa, a gente ri muito, porque ele não entende o que a gente fala e a gente tenta fazer gestos assim que não tem nada a ver. É, é bem engraçado.

Silvia: Ele mostra todos os desenhos para todo mundo. Na classe, quando ele chega, assim, elefica assim, olha, olha, toda hora. Eu falo: -"Ai, bonito, bonito!".
\end{abstract}

Nos itens analisados anteriormente aparecem sempre comentários positivos em relação ao relacionamento com o al uno surdo como senão houvesse dificuldades, porém é possível identificar relatos que dizem respeito a problemas de comunicação enfrentados na relação em ele. Parece que, inicialmente, estas dificuldades são apagadas ou são vistas como pouco importantes, ou ainda como engraçadas. Há uma crença de que a comuni cação estabel ecida é muito boa e de queos problemas são irrelevantes, apesar da vivência de experiências que revelam o contrário.

Fazer trabalhos em duplas é visto como algo que traz desespero, especialmente se a intérprete não está por perto, ou seja, trabal har em sala com conteúdos próprios da escola se mostra pouco possível pelas dificuldades efetivas de comunicação. Em jogos que, em geral, não contam com a presença da intérprete a discussão de regras ou de detal hes dos jogos são gerenciadas com dificuldades, nomeadas por Silvia como engraçadas, já que os mal-entendidos, às vezes, têm mesmo esta característica.

Assim, a relação entrealunos ouvintes esurdos não ésempretranqüila, mas cheia de barreiras e obstácul os que precisam ser vencidos a cada encontro, e quenem sempresão superados. Quando Silvia comenta sobreos desenhos trazidos por Gustavo (em geral trata-se de desenhos narrativos complexos, que descrevem uma história) diz que são bonitos, o que é um elogio/ comentário muito reduzido no confronto com aquilo que o material que ele apresenta poderia suscitar para discussão. N estes trechos é possível ver limites mais claros nos relacionamentos e uma grande simplificação das interações comunicativas.

Os relatos apresentados revelam queo aluno surdo pareceser acol hido pela classe, visto com respeito, equeconta com a amizade de vários companheiros, entretanto também revelam uma superval orização destas relações, como se não houvessem problemas e como se tudo se desenvolvesse satisfatoriamente.

As alunas falam de um ambiente feliz, no qual o aluno é querido, tem boas relações, e que todos conhecem sinais suficientes para uma comunicação bastante satisfatória. N esteambienteele se revela um bom aluno, eo seu trabalho com a intérprete é acolhido sem dificuldades, fazendo pensar em um ambiente harmonioso, no qual não existem conflitos.

Entretanto, se o olhar é mais apurado é possível perceber nos depoimentos que a língua de sinais é vista como algo difícil, trabal hosa para aprender, e que muitas vezes, é um pouco chata. Queo amigo surdo élegal, mas 
que faz coisas estranhas, que freqüentemente não são compreendidas, e que se espera que ele aprenda a fal ar efale.

Configura-seum paradoxo entreaquilo que pareceimportantequese acreditee aquilo queéefetivamente vivenciado. A relação entreal unos ouvintese surdo não se revela sempre difícil, há uma aceitação e uma compreensão de suas características, mas não se revela sempre fácil, há dificuldades de relação, de conhecimento sobre a surdez e de aceitação de certas características. Porém, os aspectos mais complexos estão escondidos, percebidos como menos importantes. Há um saldo geral positivo e isso é o que conta. Entre as crianças não há um estranhamento e apreensão em relação ao novo, que permitiria uma visão mais realística do queocorre.

\subsection{Análise da entrevista realizada com aluno Surdo ${ }^{8}$}

Para a anál ise da entrevista com o aluno surdo foram consi derados os seguintes núcleos temáticos: Relação entrealuno surdo ealunos ouvintes, Relação entrealuno surdo e professores ouvintes ealuno surdo, Representação queo aluno surdo tem do papel das intérpretes.

\section{Relação entre aluno surdo e alunos ouvintes}

I: PRIMEIRO PERGUNTAR ESCOLA SUA AMIGO MUITO VOCÊ TER (expressão facial, reforçando a pergunta) MUITO?

\section{GU: SIM}

P.: E quem são os amigos?

I: QUEM NOME AMIGO QUANTOS NOME AMIGO SEU?

GU: (expressão de pensamento, movimenta os dedos parecendo contar um, dois, três, pensa) NÃO SEI.

I: NOME UM LEMBRAR UM?

GU: (pensativo, ol ha para cima) NÃO (com a cabeça)

P. paral: N ão sabe o que? 0 nome?

I para P.: É, Não lembra o nome.

I: LEMBRAR?

GU: NÃO (com a cabeça)

P.: $M$ as lembra o sinal?

I: LEMBRAR SINAL HOMEM AMIGO SEU SINAL JEITO

GU: (faz um sinal com a mão, não dá para saber se ele refere-se a um homem ou esse gesto éo sinal de um homem) HOMEM (expressão de dúvida) (?)

I: (copia o sinal) HOMEM ? (expressões de dúvida e pergunta)

I: OUTRO, OUTRO

P.: E menina, tem alguma menina?

I: MULHER AMIGO VOCÊ TER AMIGO MULHER

GU: SIM (movimenta a cabeça, parado observando continua com a mão no

\footnotetext{
${ }^{8}$ Para transcrição da entrevista com o aluno surdo foi utilizada a notação proposta por Lacerda (1996) adaptada, onde em CAIXA ALTA está a representação dos sinais da LIBRA S utilizados, em itálico a representação da fala e (entre parênteses) comentários relativos à comportamentos que importavam para a comunicação. I éa intérprete, GU éGustavo, aluno surdo, eP a pesquisadora.
} 


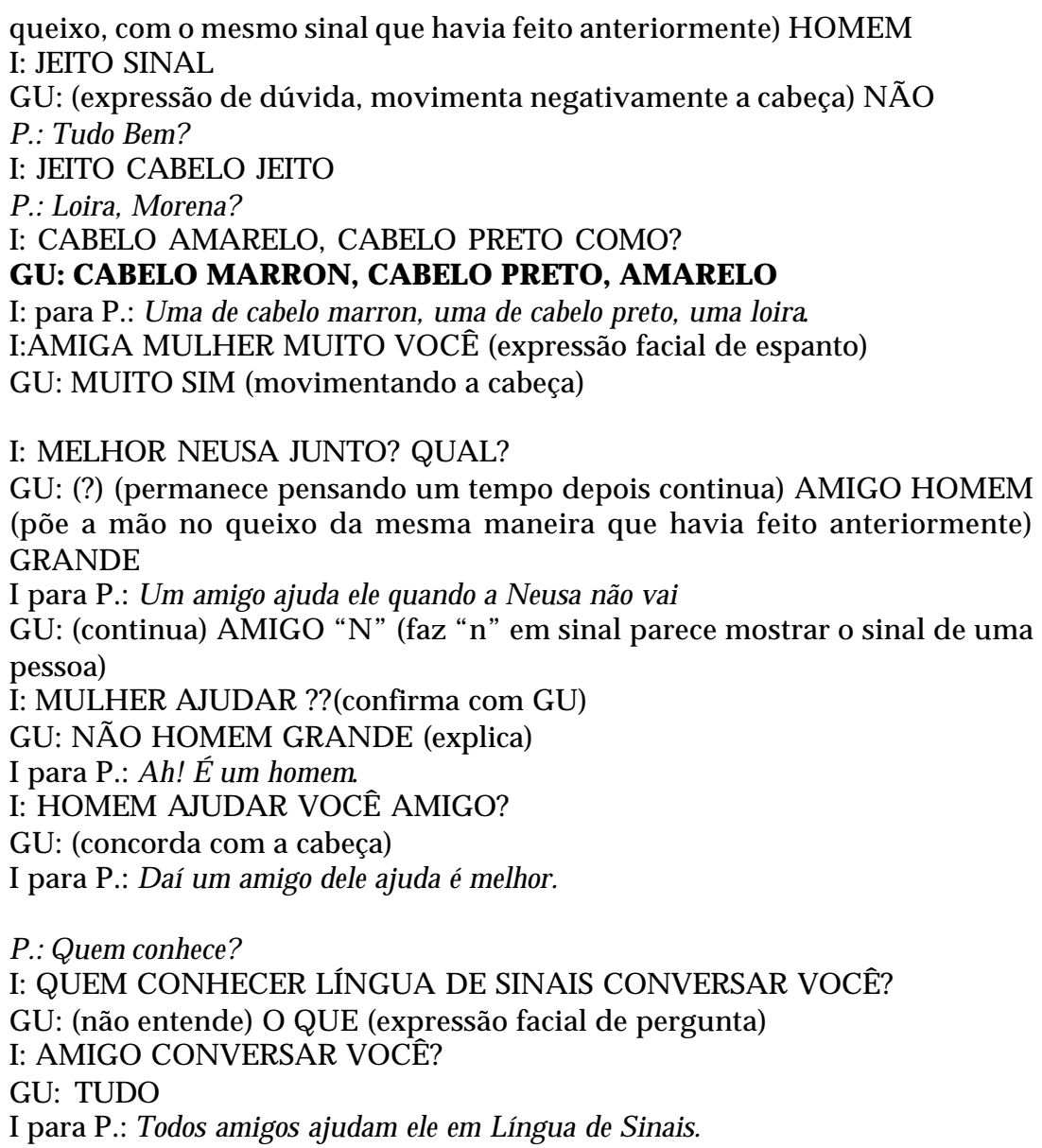

Os trechos apresentados revelam que Gustavo se sente inserido em sua classe, que tem vários amigos, tanto meninos como meninas, e que ele se relaciona esesenteajudado por eles nas tar efas escolares, também porqueconsidera que eles saibam bem a língua de sinais. Ele se refere a um certo aluno, que na ausência da intérpreteo ajuda, fazendo interpretações para auxiliá-lo. Gustavo parece pensar que os amigos domi nam satisfatoriamente a língua de sinais (a ponto de poder auxiliá-lo nas tarefas escolares) e que não existem dificuldades de comunicação entreeles, todavia isto não éreal. Os al unos conhecem al guns sinais, os usam freqüentemente em contextos em que os conteúdos a serem discutidos são relativamentesi mples, como apontado nas anál ises das entrevistas das al unas ouvintes. Ele e os amigos conversam em situações cotidianas de solução de problemas que se referem aos jogos, brincadeiras, trocas deinformações mínimas que Gustavo reconhece como satisfatórias, dada a pouca complexidade que envolvem.

Seu depoimento pode ser interpretado que, pelo fato de ter contato quase que exclusivamente com crianças ouvintes, ele pense que a forma de comunicação possível entre crianças seja esta. Elenão tem a experiência deconviver 
com outras crianças surdas fluentes em sua língua e, assim, não tem um modelo deamigos que conversem com ele de outra maneira. Elese mostra satisfeito eisso pode se dever ao fato de que essa seja a única experiência de comunicação entre pares que ele conhece!

Nestecontexto, as crianças parecem achar queo conhecimento desinais que possuem seja suficiente, se sentido seguros inclusive para ocupar o lugar da intérpretequando esta se ausenta. E Gustavo parece concordar com seus amigos, assumindo também que el es sejam capazes de interpretar para ele. O queos dados revelam é que há uma falsa consciência sobre o conhecimento que os alunos ouvintes possuem sobre língua de sinais, que pode gerar muitos problemas de comunicação e de relacionamento porque está fundamentada em al go falacioso.

Ao mesmo tempo, Gustavo revela não saber o nome dos amigos e amigas e não saber dizer o sinal que identifica cada um deles. Estefato indica que a língua de sinais, presente na sala de aula, não circula suficientemente para estabilizar informações básicas como os nomes dos companheiros. Esteaspecto foi apontado por Débora revelou não ter um sinal para si, pela fal ta de tempo para atividades destetipo, apesar desesentir muito próxima ao aluno surdo. A falta de um nome, de um elemento que identifiqueo outro indica a ausência de um aspecto fundamental para as relações pessoais. São amigos sem nome e isso não parece incomodar Gustavo.

Os alunos de modo geral acreditam que se comunicam plenamente, 0 quenão éverdade, já queem suas relações estão ausentes pontos fundamentais do contato e relacionamento entre pessoas. Esses dados fazem pensar em vínculos aparentes, mas que na realidade estão apoiados em pressupostos frágeis. Eles pensam que se conhecem, que trocam informações, mas na verdade o fazem de maneira muito parcial, distantes dos modos de relação normal mente al cançados por alunos ouvintes nas relações entresi.

\title{
Relação entre aluno surdo e professores
}

\author{
P.: E os professores, você gosta dos professores? \\ I:PROFESSOR SUA ESCOLA VOCÊ GOSTAR (expressão facial pergunta) \\ LEGAL NÃO GOSTAR? \\ P.: Qual você gosta mais? \\ I: QUAL PROFESSOR GOSTAR LEGAL MAIS LEGAL QUAL? \\ GU: (olha para intérpretecom expressão dedúvida, movimenta negativamente \\ a cabeça) NÃO \\ I: UM PROFESSOR LEGAL MAIS \\ GU: (copia sinal) MAIS \\ I: QUAL UM NOME UM? \\ P.: De português, de matemática... \\ I: QUAL PORTUGUÊS, MATEMÁTICA PROFESSOR LEGAL QUAL? \\ GU: (mostra sinal de uma pessoa em Língua de sinais) \\ I para P.: (produz o mesmo sinal) \\ I: SINAL, SINAL, QUEM SINAL PROFESSOR QUEM? \\ GU: PORTUGUÊS, CIÊNCIAS (pensando) HISTÓRIA (pensando) INGLÊS
}


I: INGLÊS GOSTAR? (expressão de pergunta)

GU: (movimenta positivamente a cabeça confirmando e depois continua) EDUCAÇÃ O FISÍCA (braço na altura do rosto faz movimento de vai e vem duas vezes)

GU: (interrompe a pergunta e continua) ARTES.

I: (chama GU) QUAL PROFESSOR GOSTAR MAIS UM?

GU: NÃO (com a cabeça)

I: (copiou sinal negativo com a cabeça) TODOS

$P .:$ A Igum professor sabe Língua de Sinais?

I: PROFESSOR SUA ESCOLA PROFESSOR SABER...

GU: (bal ança a cabeça negativamente interrompendo I ntérprete)

I: (chama GU e continua) TER PROFESSOR SABER LINGUA DE SINAIS PROFESSOR SABE LÍNGUA DE SINAIS?

GU: NÃO

I: NÃO (balança a cabeça confirmando resposta de GU)

$P$.: N enhum sabe?

I: NINGUÉM?

GU: NÃO (balança a cabeça)

$P .:$ E quando você quer conversar com esses professores como faz?

I: SE VOCÊ QUER VONTADE CONVERSAR PROFESSOR COMO VOCÊ ELE CONVERSAR?

GU: NÃO (balança a cabeça)

I: NÃ O (copia o Gu, expressão de desconfiança)?

$P .:$ ão conversa?

I: NÃO CONVERSAR VOCÊ PROFESSOR

P.: Se você quiser perguntar al guma coisa para o professor de Português como faz? I: PERGUNTAR PROFESSOR COMO VOCÊ ELE PERGUNTAR CON VERSAR? GU: (Faz o sinal da intérprete) NEUSA

GU: NEUSA PROFESSOR FALAR (pensa...)

Nos trechos destacados se pode perceber que Gustavo conhece seus professores, têm sinais para eles e para as disciplinas equetem opinião formada sobreeles. A pesar de não exprimir preferências, fazia expressões faciais ao nomear cada um que deixavam ver algumas de suas impressões sobre eles. Assim, ele revela participar das aulas, saber dos diferentes professores e dos assuntos que tratam.

Porém, é interessante ressaltar sua primeira reação à pergunta sobre como faz para conversar com seus professores. Sua expressão demonstra estranhamento em relação à pergunta revelando que, provavelmente, conversar com os professores não éuma situação usual. Só depois quea pergunta foi retomada, com alguma insistência, é que ele refere o papel da intérprete mediando estas relações, mas sua incompreensão à pergunta faz pensar que ele se dirija pouco diretamenteaos professores equeestemodo de rel ação nem Iheocorra com muita freqüência.

Em relação ao conhecimento de língua de sinais pelos professores ele afirma com segurança que nenhum deles a conhece. De fato os professores conhecem poucos sinais isolados aprendidos em oportunidades criadas no próprio 
espaço escolar. Contudo, é interessante pensar que as produções da professora tal vez não sejam muito diferentes das produções de vários colegas em classe, que usam de forma incipiente os sinais, mas ele tem uma experiência bastante consolidada com as intérpretes esabe bem o queéser um adulto fluenteem Libras, e avalia que a produção em sinais dos professores (daqueles que tentam se comunicar) é bastanterudimentar. No confronto com adultos, ser ou não fluente em língua de sinais parece ser claro para ele, o que não se observa em relação aos seus colegas.

\section{Representação que o aluno surdo tem do papel das intérpretes}

P.: Ela é professora?

I: MULHER NEUSA PROFESSOR?

GU: SIM (confirma com a cabeça, porém parece não ter compreendido a pergunta pela expressão facial)

P.: Ela é professora?

I: NEUSA PROFESSOR, NEUSA PROFESSOR?

GU: NÂO (movimenta a cabeça)

P.: 0 que ela é?

I: O QUE FAZER ESCOLA? (expressão facial duvida e pergunta)

GU: ESCOLA MUITO (não responde a pergunta)

I: (retorna a pergunta) NEUSA QUEM?

GU: (movimenta negativamentea cabeça, pensa, depois ol ha para a intérprete) NEUSA ESCOLA AJUDAR LINGUA DE SINAIS LER ESCREVER LINGUA DE SINAIS

P.: E a N eusa ajuda a professora, ela é diferente da professora é parecida o que você acha?

I: NEUSA AJUDAR PROFESSORA PARECER PROFESSORA DIFERENTE JEITO NEUSA QUAL? (expressão facial e corporal para dar entonação à pergunta)

GU: (movimenta a cabeça) DIFERENTE.

P.: Pergunta.. faz o sinal de intérprete e pergunta pra ele se ele sabe o que é um intérprete?

I: (chama GU) SABER INTÉRPRETE?

GU: SIM (com a cabeça)

I: CONHECER SINAL INTERPRETAR?

GU: SIM

P.: Q uem é intérprete! Ele conhece al gum intérprete?

I: QUEM CONHECER INTERPRETAR VOCÊ CONHECER INTERPRETAR?

GU: SIM

I: QUEM QUAL?

GU: (põe a mão no rosto) INTERPRETAR IR AMIGO AJUDAR LÍNGUA DE SINAIS TUDO SINAIS AJUDAR

I para P.: são os amigos del e que ajudam ele em Língua de Sinais.

I: O QUE FAZER (intérprete)?

GU: (pensando) LER ESCREVER SINAIS AJUDAR SINAIS ESCREVER NÃO CONHECER AJUDAR EU ENTENDER ESCREVER

I para P.: Ela ajuda quando el e não con hece depois que el e entende, ele faz sozinho. 
Sobre sua percepção sobre o trabalho realizado pelas intérpretes, Gustavo mostra ter vários conhecimentos em relação à figura de intérprete queo acompanha. Sabequeéal guém queconhecea Libras, queédiferentedo professor, quetem uma atuação específica no espaço escolar, equepodeajudá-lo emuito em áreas que ele tem dificuldade, com destaque para as questões que envolvem a linguagem escrita.

Todavia, seus depoimentos marcam também uma série de incertezas. Dianteda questão sea intérpreteé(também) professora ele pareceu ficar um pouco confuso o que émuito razoável, já que as intérpretes funcionam como professoras para ele em muitos contextos, dando dicas, esclarecendo pontos, auxiliando na compreensão de certos argumentos, é natural que ele as reconheça como diferentes dos outros professores da classe (falantes e que ocupam o comando da sala de aula), mas, em certo sentido, também professoras porque Ihe ensinam coisas. Ele também refere que a intérprete está na classe para auxiliar a todos, inclusive os alunos ouvintes, talvez nestemomento reconhecendo-a mais como uma professora auxiliar de classe, que como sua intérprete. Estes dados mostram que para Gustavo o papel deintérpreteem sala deaula éno mínimo amplo.

Em relação a como sesentecom a ausência da intérprete, ele refereque nestes momentos os amigos assumem o papel inter pretan do equeisso émuito bom! Porém, anal isando suas reações e uma pequena conversa ocorrida após a entrevista, ele diz que quando a intérprete não está ele pode trabal har menos, ele é menos solicitado, e com isso ele tem uma folga! N esse sentido a ausência da intérprete significa um descanso e um certo alívio em relação às tarefas freqüentes no espaço escolar. Como as situações de ausência das intérpretes foram poucas, talvez ele não tenha uma real dimensão do que seja o enfrentamento de conteúdos sem o trabal ho de interpretação. Todavia, revela que o trabal ho conjunto com a intérprete é pesado elaborioso para ele.

A leitura da entrevista de Gustavo faz pensar que ele tenha uma compreensão particular de sua escolarização. Freqüentar uma classe de ouvintes não é uma opção para Gustavo, mas al go normal, e o único contexto escolar que conhece. Para ele é normal ser acompanhado cotidianamente por uma intérprete, pois durante toda sua vida escolar teve ao seu lado al guém interpretando.

Em relação aos seus amigos, sabe que conhecem alguns sinais e os reconhece como tendo domínio da língua desinais, real izando uma comunicação efetiva com eles. Reconhece que seus professores não conhecem sinais, mas isso não traz problemas porquetem a intérprete ao seu lado queo ajuda em suas tarefas escolares. Não parece se sentir sozinho ou isolado. Vive em uma ilha, dentro de sua sal a de aula e isso Ihe parece adequado; vendo seu relacionamento restrito às intérpretes eas poucas trocas dialógi cas com os al unos como natural.

Entretanto, para aqueles queconhecem a vivência escolar entrecrianças ouvintes, as possibilidades de trocas entre alunos e professores e a riqueza de informações quecirculam quando seestá em um grupo com o qual se compartilha 
uma mesma língua, a situação de Gustavo parece insólita: em uma quinta série não conhecer o nome dos amigos, não serelacionar diretamente com os professores, ter apenas um interlocutor efetivo no espaço escolar, estar sempreacompanhado por um adulto, não é al go que possa ser chamado de satisfatório. Ele por não conhecer outra realidademostra-se bem adaptado a sua situação. Como não conhece algo diferentepensa/ acredita que esta convivência seja boa, ese satisfaz com ela. Cabe refletir se esta vivência escolar é realmente plena, e se este é o espaço educacional que se deseja para os alunos surdos.

\section{Considerações finais}

As entrevistas parecem indicar que as crianças surdas e ouvintes desenvolvem uma relação de respeito e amizade ente si, nesta experiência de inclusão. Há respeito pela diferença que é materializada pelo uso e respeito pela Libras, e pelo interesse em conhecer a realidade do outro e dela se aproximar.

Todavia, tudo isto parece ser feito deforma superficial - sem um efetivo engajamento: al unos ouvintes dominam poucos sinais, que permitem apenas trocas furtivas sobre certos acontecimentos. $O$ al uno surdo parece se satisfazer com isso, já que não conhece outra realidade de interação com pares. Elenão exige/ procura aprofundar suas relações com os amigos ouvintes. A s intérpretes mostram ocupar lugar fundamental nesta prática de inclusão mediando a relação entreas crianças e com os professores (tudo o que foi apurado não teria lugar sem a presença de intérpretes), contudo, o aluno surdo mostra-se, em muitos aspectos, excluído: não conhece o nome de seus colegas; sabe pouco sobre eles e é pouco conhecido por eles; não podem/ conseguem conversar sobretemáticas mais aprofundadas, o que configuraria um relacionamento maissemel hanteàqueleencontrado entreos alunos ouvintes. A lém disso, o aluno surdo não demonstra ter um relacionamento mais amplo com seus professores. Ele freqüenta a classe, mas sua inserção/ inclusão nela mostra-se bastante parcial.

Mesmo num ambienteem quea surdez é considerada, com a presença deintérprete de Libras e com respeito à língua utilizada pelos surdos, a dificuldade deacesso a uma língua diferente (afinal os ouvintes não têm domínio de Libras); a presença de um único surdo em sala, tendo com interlocutor apenas o intérprete cria condições muito diferentes daquelas enfrentadas pel os alunos ouvintes: trocas comunicativas limitadas, sem maior aprofundamento das relações interindividuais, pouca participação nas dinâmicas e nas ocorrências em sala deaula, indicando que pressupostos necessários a uma prática inclusiva de educação não se mostram presentes, apontando para possibilidades e limites das práticas inclusivas, especialmente dirigidas a alunos surdos. Tais resultados merecem ser consideradas nos debates e na implementação de políticas dirigidas à inclusão escolar. 


\section{Referências}

BOTELHO, P. Segredos e Silêncios na Interpretação dos Surdos. Belo H orizonte: Autêntica, 1998.

BUNCH, G. An interpretation of full inclusion. A merican A nnals of the D eaf, v. 139, n. 2, p.150-152, 1994.

CAPIRCI, O.; CATTANI, A; ROSSINI, P.; VOLTERRA, V. La lingua dei segni come seconda lingua nella scuola elementare. Psicologia Clinica dello Sviluppo, 2, p. 301-311, 1997.

COHEN, O. P. An administrator's view in inclusion for deaf children. A merican A nnals of the D eaf, v.139, n. 2, p.159-161, 1994.

DECLARAÇÃO DE SA LAMANCA elinhas deação sobrenecessidades educativas especiais. Brasília: CORDE, 1994.

GÓES, M.C.R de Linguagem, surdez e educação. Campinas: Autores A ssociados, 1996.

KIRCHNER, C. J. Co-enrolment as an inclusion model. A merican A nnals of the D eaf, v. 139, n. 2, p. 163-164, 1994.

LACERDA, C. B. F. O s processos dialógicos entrealuno surdo eeducador ouvinte: examinando a construção de conhecimentos. 1996, 159f. Tese (Doutorado) - UniversidadeEstadual deCampinas, Campinas, 1996.

. A inserção da criança surda em classe de crianças ouvintes: focal izando a organização do trabalho pedagógico. In: REUNIÃO ANUAL DA ANPED, 14, 2000. Anais... Caxambu: Anped. Disponível em: www.anped.org.br, 2000.

; MANTELATO, S. A. C. As diferentes concepções delinguagem na prática fonoaudiológica junto a sujeitos surdos In: LACERDA, C.B.F. et al. Fonoaudiologia: surdez eabordagem bilíngüe. São Paulo: Plexus, 2000. p. 21-41.

LAPLANE, A L. F. Notas para uma análise dos discursos sobre inclusão escolar, In: GOES, M. C. R.; LAPLANE, A. L. F. (Org.) Políticas e práticas de educação inclusiva. Campinas: Autores Associados, 2004. $p 121-147$.

MAZZOTA, M.J.S. Educação especial no Brasil: história e políticas. São Paulo: Cortez, 1996.

MOURA, C. O Surdo: caminhos para uma nova identidade. Rio de Janeiro: Revinter, 1999.

ROSSELA, D. Studio sull'integrazione e le relazione sociali di due bambini sordi inseritti in classe com bambini udenti. 2000/2001, 90f. Tesi di Laurea. Universitádegli studi di Roma “LaSapienza”: Roma. SASSAKI, R. K. Inclusão: construindo uma sociedade para todos. Rio de Janeiro: WVA, 1997.

SILVEIRA BUENO, J. G. A Educação do deficiente auditivo no Brasil. In: BRASIL, Secretaria de Educação Especial. Ten dências e desafios da Educação Especial. Braślia: SEESP, 1994.

STIN SON , M. S; LIU, Y. Participation of deaf and hard-of-hearing students in classes with hearing students. Journal of deaf Studies and deaf Education, v.4, n. 3, p.191-202, 1999.

TARTUCI, D. A experiência escolar de surdos no ensino regular . 2001, 167f. Dissertação (Mestrado) Universidade Metodista de Piracicaba, Faculdade de Educação, Piracicaba, 2001.

TERUGGI, L. A U na Scuola, due lingue: I'esperienza di bilinguismo della scuola dell'Infanzia ed Elementaredi Cossato. Milano: FrancoAngelli, 2003.

VYGOTSKY, L.S. A construção do pensamento e da linguagem. São Paulo: Martins Fontes, 2001.

YARGER, C. C. Educational Interpreting: understanding the rural experience. A merican Annals of the D eaf, v. 146, n. 1, p.16- 26, 2001. 
APÊNDICE

Roteiro da entrevista com Aluno surdo

Em que série que você esta? Em que escola?

Quantas professoras(es) você tem?

Estes professores (as) dão quais disciplinas?

Você gosta mais de algum professor(a)? Porque?

O que você acha que a N. (ILS) faz na escola?

Porque ela faz língua de sinais?

Quando a N . falta, como é pra você assistir aula?

Você trabalhou com diferentes ILS, qual você gostou mais?Porque?

Quando você quer conversar com seus amigos, precisa chamar a N. ou você conversa sozinho?

Se você quiser convidar os amigos para sua festa de aniversário como vai fazer?

Quando você quer conversar com a professora você chama a N. ou conversa com a professora?

Quando uma pessoa é interprete o que ela faz?

A N. ajuda você? Como?

Seus amigos sabem língua de sinais?

Você gostaria que seus amigos soubessem língua de sinais como a N .?

O que você gostaria de conversar com os amigos?o que você conversa com eles?

Quem sabe língua de sinais é surdo ou ouvinte?

Quem é surdo na sua escola?

$\mathrm{E}$ a $\mathrm{N}$ é surda ou ouvinte?

O que você acha da sua escola e dos seus amigos?

\section{Roteiro da entrevista com alunos ouvintes}

Vocês estão na classe com o G. desde o ano passado?

Como éque é estudar com ele? O que aconteceu? O que éfácil? O queé difícil? Vocês já fizeram trabal ho em grupo com ele alguma vez, ou não?

Quando el e faz os sinais vocês entendem?

Você tenta conversar com ele ou fica mais de longe, como é?

Como é que é seu sinal? Você tem um sinal?

E se você precisar pedir um lápis emprestado para ele, você pede?

Como é a intérprete na sala de aula? Qual é a tarefa dela? Vocês conversam com ela? Vocês pedem ajuda para ele? Para ela, como é que é? 
Você prefere conversar com ele, você fazendo os sinais, ou prefere que ela fale para ele o que você quer falar?

Você acha que a intérprete faz a direitinho a comunicação entre vocês?

E nas aulas? É diferente de uma aula para outra?

A presença do G. e da intérprete atrapal ha vocês em alguma coisa?

Quando a intérprete não está, o que acontece?

E fora da sala de aula, no pátio, no intervalo, na Educação Física, como é que vocês se relacionam com ele?

Vocês sabem sinais? Como é aprender a língua de sinais?

E como aluno, o que vocês acham dele? Vocês acham que ele é um menino que está aprendendo, ou não?

O que vocês sabem surdez? O que imaginam que aconteceu com ele?

Será que tem bastante gente surda pelo mundo ou não? O que vocês acham?

Você já tinha visto al gum surdo antes do Guilherme? 